Quaestio facti. Revista Internacional sobre Razonamiento Probatorio Quaestio facti. International Journal on Evidential Legal Reasoning Vol. 1 | 2020 pp. 285-298 Madrid, 2020

DOI: $10.33115 /$ udg_bib/qf.i0.22373 Marcial Pons Ediciones Jurídicas y Sociales (C) Raymundo Gama ISSN: 2604-6202

Recibido: 24/06/2019 | Aceptado: 22/11/2019

\title{
PRUEBA Y PERSPECTIVA DE GÉNERO. UN COMENTARIO CRÍTICO ${ }^{1}$
}

\author{
Raymundo Gama \\ Instituto Tecnológico Autónomo de México \\ raymundo.gama@itam.mx
}

RESUMEN: Este trabajo ofrece una aproximación inicial a la relación entre prueba y perspectiva de género. En primer lugar se plantea que al hablar de prueba con perspectiva de género habría que reconocer la vinculación de esta última con el feminismo y las perspectivas feministas sobre la prueba. Desvinculada de los movimientos feministas, la perspectiva de género corre el riesgo de convertirse en una visión desprovista del potencial reivindicativo y crítico que le dio origen. En segundo lugar, el alcance de la perspectiva de género en el ámbito probatorio comprende la prueba en general. Prácticamente todos los temas y problemas probatorios son susceptibles de examinarse con perspectiva de género. Finalmente, la tesis sobre la exigencia de corroboración de la declaración de la víctima requiere examinarse con perspectiva de género. Una regla de esa naturaleza opera en detrimento de las víctimas y refuerza el escepticismo estructural hacia su credibilidad.

PALABRAS CLAVE: prueba y perspectiva de género, perspectivas feministas sobre la prueba, credibilidad, declaración de la víctima, corroboración.

1 Agradezco la lectura y comentarios críticos de las profesoras Ana Micaela Alterio y Natalia Morales. He podido discutir algunas de las ideas contenidas en este trabajo en el Seminario de Fundamentos del Derecho Procesal de la Universidad de Chile, en el Tribunal Electoral del Poder Judicial de la Federación y en la Universidad de Northwestern. Agradezco todos los comentarios y sugerencias recibidas en esos eventos. 


\section{A GENDER PERSPECTIVE ON EVIDENCE. A CRITICAL ASESSMENT}

ABSTRACT: This paper offers a preliminary analysis of a gender perspective on evidence. It shows the connection between a gender perspective on evidence with feminism and feminist perspectives on evidence. It also shows that the scope of a gender perspective on evidence covers the entire field of Evidence. It finally shows that the corroboration requirement could be examined from a gender perspective. The corroboration requirement is inimical to the victims and strengthens a structural skepticism about her credibility.

KEYWORDS: gender perspective on evidence, feminist perspectives on evidence, victim testimony, credibility, corroboration requirement.

SUMARIO: 1. Introducción.—2. La relación entre prueba y perspectiva de género.—3. Testigo único y exigencia de corroboración.-4. Conclusión.- 5. Bibliografía.

Feminist method offers a fascinating perspective on evidence law, because feminism, like evidence, is concerned with how stories are heard and how society determines credibility

Aviva Orenstein

\section{INTRODUCCIÓN}

¿En qué sentido y hasta qué punto la prueba puede estar afectada por cuestiones de género? ¿Qué aspectos de la prueba serían susceptibles de examinarse con perspectiva de género? ¿En qué se traduce la utilización de esta perspectiva en el ámbito probatorio? ¿Qué es lo que los tribunales hacen de hecho cuando emplean la perspectiva de género en la prueba? ¿Cuál es la relación entre perspectiva de género y perspectivas feministas sobre la prueba? ¿Habría alguna diferencia entre analizar la prueba con perspectiva de género y analizarla desde una perspectiva racional? ¿Habría alguna metodología para examinar la prueba con perspectiva de género?

Estas preguntas pueden resultar relevantes para examinar la relación entre prueba y perspectiva de género. Sorprendentemente, sin embargo, este tema no figura en la agenda quienes se ocupan de la prueba ${ }^{2}$. Parafraseando a Twining, al llamado a tomar los hechos en serio habría que sumar la necesidad de tomar en serio la perspectiva de género sobre la prueba.

Este trabajo ofrece una aproximación inicial a la relación entre prueba y perspectiva de género a partir de un comentario crítico a las tesis planteadas por el Magistrado José Luis Ramírez Ortiz en el artículo titulado "Testimonio único de la víctima y perspectiva de género en el proceso penal de la presunción de inocencia». 2016.

2 Hay desde luego algunas excepciones. Véase Fuentes Soriano, 2009; Di Corleto, 2017; Noya 
En primer lugar se plantea que al hablar de prueba con perspectiva de género habría que reconocer la vinculación de esta última con el feminismo y las perspectivas feministas sobre la prueba. Desvinculada de los movimientos feministas, la perspectiva de género corre el riesgo de convertirse en una visión desprovista del potencial reivindicativo y crítico que le dio origen. En segundo lugar, el alcance de la perspectiva de género en el ámbito probatorio comprende la prueba en general. Prácticamente todos los temas y problemas probatorios son susceptibles de examinarse con perspectiva de género. Finalmente, la tesis sobre la exigencia de corroboración de la declaración de la víctima requiere examinarse con perspectiva de género. Una regla de esa naturaleza opera en detrimento de las víctimas y refuerza el escepticismo estructural hacia su credibilidad.

Por razones de espacio, en este trabajo no es posible dar una respuesta a todas las preguntas apuntadas anteriormente, pero sí al menos ofrecer algunos elementos para su análisis con la intención de sugerir algunos temas y rutas de investigación.

\section{LA RELACIÓN ENTRE PRUEBA Y PERSPECTIVA DE GÉNERO}

La pregunta central que plantea José Luis Ramírez Ortiz es qué puede aportar la perspectiva de género en el ámbito probatorio y en el tratamiento de la declaración de la víctima en aquellos casos en que no haya pruebas que corroboren su dicho. Su tesis es que en la etapa de juicio, la perspectiva de género desempeña una función epistémica al ofrecer una herramienta que permite al juzgador identificar y visibilizar los estereotipos de género que se presentan en el razonamiento probatorio bajo el ropaje de pretendidas máximas de experiencia. La perspectiva de género permitiría así desactivar máximas de experiencia espurias y estereotipadas, sustituyéndolas por criterios cognoscitivos adecuados con los que el juzgador pueda realizar inferencias probatorias y valorar las pruebas sin prejuicios ni estereotipos de género.

No obstante, Ramírez Ortiz sostiene que la perspectiva de género no puede emplearse para subsanar la insuficiencia de un medio probatorio, dándole un mayor peso probatorio que el que amerita. Concretamente, afirma que la perspectiva de género no podría sustentar una sentencia condenatoria con la sola declaración de la víctima si ésta no se encuentra corroborada. Al respecto, Ramírez Ortiz distingue dos sentidos de corroboración, uno fuerte y uno débil. Corroboración en sentido fuerte, cuando hay una prueba de fuente distinta que sustenta el hecho principal y corroboración en sentido débil, cuando hay una prueba de fuente distinta que sustenta alguno o algunos de los hechos secundarios. De estos dos sentidos Ramírez Ortiz entiende la exigencia de corroboración en sentido débil.

Además de una función epistémica, Ramírez Ortiz sostiene que la perspectiva de género en el ámbito probatorio desempeña una función heurística en la etapa de investigación, en tanto permite formular hipótesis adecuadas sobre los hechos de la causa, así como allegarse de las pertinentes fuentes de prueba adicionales a la declaración de la víctima que podrán ser posteriormente empleadas en el juicio. 
Es por tanto en la fase de investigación donde a su juicio deberían volcarse los esfuerzos por contar con un material probatorio suficiente, por lo que no cabría compensar un caudal probatorio insuficiente con la atribución de mayor peso a la declaración de la víctima en ausencia de otras pruebas que la corroboren.

De acuerdo con este autor, la única manera de que se produzca una verdadera convicción racional de la prueba que deje de lado una convicción meramente subjetiva del juzgador es exigir que la declaración de la víctima esté corroborada con un dato probatorio externo y de fuente distinta a la propia declaración. Para Ramírez Ortiz, en suma, la concepción racionalista de la prueba exigiría la corroboración del testimonio.

En este apartado se analiza la tesis de Ramírez Ortiz sobre la función de la perspectiva de género en el ámbito probatorio, dejando su tesis sobre la exigencia de corroboración de la declaración de la víctima para el siguiente apartado.

Al hablar de prueba y perspectiva de género habría que comenzar examinando estos dos conceptos. En relación con el segundo, en lugar de ofrecer una definición más de lo que se entiende por "perspectiva de género" o de repetir algunas de las explicaciones recurrentes al hablar de esta perspectiva me limitaré a destacar un aspecto que no suele hacerse explícito: la vinculación de la perspectiva de género con las teorías feministas.

La perspectiva de género es un concepto y una herramienta surgida y construida desde el feminismo para identificar, develar y corregir las diferentes situaciones y contextos de opresión y de discriminación hacia las mujeres y personas LGTTT$\mathrm{BIQ}^{3}$. Desvinculada de las teorías feministas de las que surge, la perspectiva de género pierde buena parte de la fuerza y reivindicación que le dio origen. Esta falta de reconocimiento conduce a que en ocasiones la perspectiva de género es simplemente mencionada más que efectivamente utilizada e incorporada, quedando en una mera referencia genérica que no cuestiona las causas y la continuidad de prácticas discriminatorias. Es necesario subrayar y destacar la raíz feminista de la perspectiva de género porque en el empleo y difusión de esta perspectiva como política pública aplicada de manera transversal a un sinfín de disciplinas y actividades la palabra "feminismo» suele quedar oculta. Al hablar de prueba y perspectiva de género, por tanto, habría que incorporar las perspectivas y métodos feministas al ámbito la prueba.

En Estados Unidos e Inglaterra, las perspectivas feministas sobre la prueba aglutinan a un conjunto de feministas que desde los años noventa han identificado y cuestionado las implicaciones de género de las reglas, prácticas, presupuestos e instituciones probatorias, así como la manera en que la prueba conduce o puede conducir a situaciones de discriminación y de opresión hacia la mujer ${ }^{4}$.

3 Ciertamente, en tanto herramienta analítica, la perspectiva de género no solo examina la manera en que el Derecho y las prácticas jurídicas discriminan a las mujeres, sino también a otros grupos discriminados por razón de sexo o género como las personas LGTTTBIQ.

4 Entre los trabajos que plantean la incorporación de perspectivas feministas a la prueba, véanse Kinports, 1991; Mack, 1993: 27-353; Taslitz, 1998; Orenstein, 1999: 509 ss.; Childs y Ellison, 2000 . 
La aplicación de la perspectiva de género en la prueba es aún incipiente en la tradición continental, particularmente en Latinoamérica y España. Han sido principalmente los órganos jurisdiccionales, la Comisión y la Corte Interamericana de Derechos Humanos ${ }^{5}$, la Comisión Interamericana de Mujeres, la Corte Penal Internacional y el comité de la $\mathrm{CEDAW}^{6}$ quienes han establecido la incorporación de la prueba con perspectiva de género en áreas especialmente susceptibles para el análisis con perspectiva de género como el derecho penal y los delitos sexuales, pero también en áreas en principio menos evidentes como juicios de seguridad social ${ }^{7}$, derecho familiar, derecho civil, entre otras materias.

Así, han planteado, por ejemplo, que la prueba debe valorarse con perspectiva de género, que se tienen que cuestionar e interpretar los hechos desechando estereotipos de género, que la declaración de la víctima tiene un valor preponderante o que es un testigo cualificado, que se deben revisar las reglas de carga de la prueba, que se debe eliminar la exigencia de corroboración en los delitos sexuales, que se tienen que erradicar las prácticas dirigidas a reducir la credibilidad de las declaraciones de las mujeres, así como eliminar y desmontar creencias afianzadas sobre el comportamiento «esperable» de las víctimas, entre muchos otros temas.

José Luis Ramírez Ortiz afirma que la perspectiva de género en el ámbito de la prueba cumple una función epistémica al permitir identificar y eliminar máximas de experiencia espurias y estereotipadas de género empleadas en la valoración de las pruebas. Este es sin duda un buen punto de partida para analizar la relación entre prueba y perspectiva de género: examinar las diferentes maneras en que los estereotipos de género inciden en el razonamiento probatorio.

Sin embargo, la perspectiva de género en el ámbito probatorio no se reduce a este aspecto. Su potencial es más amplio y comprende la prueba en general ${ }^{8}$. Prácticamente todos los temas y problemas probatorios serían susceptibles de examinarse con perspectiva de género: la concepción de los hechos en el proceso, los presupuestos

$5 \mathrm{CIDH}$, Acceso a la Justicia para las Mujeres Victimas de Violencia en las Américas, EA/Ser.L/V/II. Doc. 68, 20 de enero de 2007. CIDH, Informe de Fondo No. 89/08, Inés Fernández Ortega y Otros, México, 30 de octubre de 2008; Corte IDH, caso González y otras ("Campo Algodonero») vs. México (sentencia de 16 de noviembre de 2009); Corte IDH, caso Fernández Ortega y otros vs. México (sentencia de 30 de agosto de 2010; Corte IDH, caso Rosendo Cantú y otra vs. México (sentencia de 31 de agosto de 2010).

6 Véase Recomendación General número 33 sobre el acceso de las mujeres a la justicia del Comité para la Eliminación de toda discriminación contra la mujer. Dicha recomendación contiene varios puntos y recomendaciones específicas sobre la prueba.

${ }^{7}$ Recurso de Suplicación núm. 0001027/2016. Sala de lo Social del Tribunal Superior de Justicia de la Comunidad Autónoma de CANARIAS. Ponente Gloria Poyatos Matas.

8 En este sentido, la perspectiva de género retoma la crítica feminista al Derecho por su carácter pretendidamente neutral, objetivo y avalorativo, planteando que esta visión refleja una perspectiva masculina, blanca, heterosexual, económicamente privilegiada y cisgénero que opera beneficiando a ciertos grupos, en detrimento de otros grupos históricamente afectados. Esta es la conocida crítica planteada por Catharine A. MacKinnon en su influyente ensayo titulado Marxist, Method and the State: An agenda for Theory. Mackinnon, 1982. 
epistemológicos de la prueba, los problemas de percepción e interpretación de los hechos, la construcción social y normativa de los hechos jurídicamente relevantes, la calificación jurídica de los hechos, los enunciados generales empleados como máximas de la experiencia o reglas de la sana crítica, las inferencias probatorias, los poderes probatorios del juez, la valoración de las pruebas y el análisis de credibilidad, la relevancia de las pruebas, la admisibilidad y exclusión de las pruebas, las reglas de carga de la prueba, el estándar de prueba, las instituciones del derecho probatorio y las reglas de la prueba en general, la práctica de ciertas pruebas como el interrogatorio y el contrainterrogatorio, la prueba testimonial, la construcción de historias y narrativas, las pruebas periciales y científicas y la enseñanza de la prueba?

Las perspectivas feministas de las pruebas en Estados Unidos han analizado muchos de estos temas ${ }^{10}$. En nuestra tradición se podría hacer un trabajo análogo y los avances que se han hecho en otras latitudes podrían ser muy útiles para nuestros propios desarrollos en la materia.

De hecho, algunos de los planteamientos realizados por las perspectivas feministas de la prueba resultarán familiares para quienes suscriben una concepción racional de la prueba. En los siguientes párrafos mostraré cómo a partir de las propias herramientas conceptuales elaboradas por la concepción racional de la prueba se puede dar cuenta de la perspectiva de género en el ámbito de la prueba.

En este contexto, es importante destacar que la concepción racional de la prueba es en buena medida convergente con lo que se plantea desde las perspectivas de género feministas sobre la prueba. Pero esto dicho sin ningún ánimo de autocomplacencia. La perspectiva de género en el ámbito probatorio mantiene abierta la crítica ahí donde la concepción racional de la prueba parece insistir en la pretensión de neutralidad y objetividad de los métodos y presupuestos de la concepción racional de la prueba ${ }^{11}$.

$\mathrm{Al}$ igual que el objetivismo crítico o realismo crítico, las epistemologías feministas cuestionan la idea de una realidad que está ahí fuera esperando a ser conocida, la escisión entre el observador y lo observado y la creencia de que el observador no tiene interacción ni participa en la construcción de la realidad. Asimismo, las epistemologías feministas destacan el papel de los sujetos y sus experiencias en la construcción de la realidad, la manera en que las construcciones de género influyen en nuestras concepciones sobre el conocimiento, la objetividad, las prácticas de investigación y justificación y, en general, la manera en que las prácticas epistémicas afectan y

9 Este es solamente un elenco de temas que podrían ser susceptibles de examinarse con perspectiva de género. No se está sugiriendo que la perspectiva de género justifique en todo caso la modificación de las cargas de la prueba o la modificación del estándar de prueba. Simplemente se plantea que estos temas pueden analizarse desde la perspectiva de género y examinar, por ejemplo, qué es lo que los tribunales hacen al pretender aplicar esta perspectiva y si resulta justificado o no.

10 Un elenco de estos temas, con abundante bibliografia secundaria, puede encontrarse en Childs y Ellison (eds.), 2000. Un recorrido útil por la literatura feminista sobre la prueba puede encontrarse en Orenstein, 1999.

11 Véase al respecto Nicolson, 2000. 
discriminan a la mujer (por ejemplo, negándole autoridad epistémica mediante descuentos de credibilidad basados en estereotipos) ${ }^{12}$. Por otra parte, las epistemologías feministas plantean la necesidad de tener en cuenta y privilegiar el contexto del sujeto epistémico, la idea de un conocimiento socialmente situado y un punto de vista feminista que tome en cuenta las experiencias de las mujeres como punto de partida ${ }^{13}$.

No es posible desarrollar en este momento todos estos puntos por lo que me limitaré a mostrar la manera en que las construcciones de género están presentes y pueden llegar a afectar nuestra percepción e interpretación de los hechos. Al respecto, la reconstrucción que ha planteado Daniel González Lagier puede servir para este propósito. Nuestra red de conceptos, categorías, recuerdos, teorías y máximas de experiencia (lo que Mosterín y González Lagier identifican como «el Transfondo») estaría también conformada por construcciones de género. Todos estos criterios «dirigen de algún modo nuestras percepciones y actúan como criterio de selección de los datos que recibimos" produciendo una dependencia de la percepción respecto de factores socioculturales (GonZÁLez LaGier, 2013: 22). De este modo, la percepción no sería una actividad pasiva y desvinculada de los sujetos, «la percepción resulta afectada por el aprendizaje, la motivación, la emoción y todo el resto de características permanentes y momentáneas de los sujetos» (SANTORO, 1979: 78 ss.).

El caso de Mariana Lima, una mujer que fue víctima de feminicidio por su pareja, un policía judicial del Estado de México, puede servir para ilustrar el problema de las percepciones que refiere González Lagier y la función heurística de la perspectiva de género a la que alude Ramírez Ortiz. Este caso fue inicialmente tratado, investigado y archivado como si se tratara de un suicidio, atendiendo a lo que había planteado su pareja y victimario, así como sus compañeros investigadores, sin que se cuestionaran los hechos, se analizaran las pruebas, ni se examinara la muerte violenta de esta mujer con perspectiva de género ${ }^{14}$. Los agentes ministeriales percibieron e indagaron los hechos de manera sesgada y tomando como única hipótesis el suicidio. Nada de lo que percibieron (que el cuerpo de Mariana Lima presentara golpes, que parecería recién bañada, la forma en que se encontró su cuerpo, la existencia de un cordón con un nudo entre muchos otros hechos) les hizo pensar en otra hipótesis que no fuera la del suicidio.

La perspectiva de género estaría también presente en la interpretación de los hechos. Siguiendo nuevamente a González Lagier, interpretar un hecho consiste en subsumir un hecho individual en una clase de hechos. Tal operación de subsunción se lleva a cabo a partir de determinados criterios, conceptos, máximas de experiencia

12 Véase Fricker, 2007 y Tuerkheimer, 2017.

13 Es importante advertir que las epistemologías feministas no están exentas de críticas. Véase especialmente la crítica de HAACK, 1998.

${ }_{14}$ Amparo en revisión 554/2013. 25 de marzo de 2015. Primera Sala. Suprema Corte de Justicia de Justicia de la Nación. Véase también la tesis surgida de este asunto, con el rubro FEMINICIDIO. LAS AUTORIDADES ENCARGADAS DE LA INVESTIGACIÓN DE MUERTES VIOLENTAS DE MUJERES TIENEN LA OBLIGACIÓN DE REALIZAR LAS DILIGENCIAS CORRESPONDIENTES CON BASE EN UNA PERSPECTIVA DE GÉNERO. 
con los que interpretamos el mundo. Estos criterios nos llevan a interpretar los hechos de un modo u otro, lo que pone de relieve la relatividad de las interpretaciones respecto del criterio, concepto o máxima empleada. «Es obvio -escribe González Lagier- que no todas las culturas comparten el mismo Transfondo, y es obvio que no lo hacen ni siquiera todos los individuos de una misma cultura. Qué nos asegura que sujetos distintos, pertenecientes a distintas culturas o incluso a una misma hagan interpretaciones coincidentes de un mismo hecho» (GonzÁlez Lagier, 2013: 23).

La reconstrucción de González Lagier permite ilustrar cómo un mismo hecho puede ser interpretado de distintas maneras y que entre los criterios que utilizamos para llevar a cabo tales interpretaciones pueden estar presentes construcciones de género, sesgos, prejuicios, creencias, etc. Nuestras interpretaciones de los hechos, por tanto, son susceptibles de examinarse desde la perspectiva de género. Además, como advierte el propio González Lagier, «la percepción y la interpretación de los hechos no son procesos totalmente independientes, sino que se condicionan mutuamente».

El caso conocido como «los Porkys" puede servir para ilustrar la manera en que nuestras interpretaciones pueden estar sesgadas por estereotipos de género. En este caso, Daphne, una joven de 17 años fue víctima de abuso sexual, violación equiparada y violación. El Juez de Distrito que examinó el caso (un juicio de amparo en contra del auto de formal prisión por el delito de abuso sexual) ${ }^{15}$ consideró que no se actualizaba el elemento de estado de indefensión establecido en la legislación entonces vigente del delito de abuso sexual en el Estado de Veracruz. Interpretó que los hechos ocurridos en el interior del vehículo al que se introdujo a Daphne no actualizaban la indefensión, pues a pesar de que Daphne fue introducida en un vehículo en el que viajaban cuatro varones, que se sentó en el asiento de atrás entre dos de ellos, que le quitaron el teléfono celular que llevaba y no sabía a dónde se dirigía y que, estando en el asiento trasero, uno de los sujetos que viajaban a su lado comenzó a manosearla y tocarle los pechos, mientras que el sujeto que viajaba al otro lado del asiento introdujo sus dedos en su vagina, ella pudo trasladarse al asiento de enfrente del vehículo en movimiento.

Adicionalmente, la perspectiva de género podría ilustrar no solo la interpretación de los hechos, sino la radicalización de los problemas de interpretación. Desde perspectivas posmodernas, algunos autores feministas sobre la prueba han llegado a afirmar que no hay hechos, sólo interpretaciones de los mismos (Nicolson, 2000: 20). Sin llegar al punto de abrazar esta tesis, coincido con González Lagier en su análisis del escepticismo radical al señalar que habría «factores que 'deforman' e 'impiden' nuestra percepción de la realidad», desde «teorías y concepciones acerca del mundo o

15 Art. 182. Código Penal para el Estado de Veracruz. A quien, sin llegar a la cópula o a la introducción vaginal, anal u oral, abuse sexualmente de un menor, agraviando su integridad física o moral, en actos públicos o privados, aprovechándose de la ignorancia, indefensión o extrema necesidad económica o alimentaria, o de su estatus de autoridad respecto de la víctima, se le impondrán de cinco a diez años de prisión y multa de hasta doscientos cincuenta días de salario. 
algún aspecto del mismo, pero también valoraciones, intereses, factores psicológicos individuales, etc. "(GonzÁlez LAGIER, 2013).

La sentencia de la Audiencia Provincial de Navarra en el caso conocido como «la Manada» puede examinarse con perspectiva de género en distintos aspectos, incluyendo el tratamiento de los problemas de percepción e interpretación de los hechos que se producen al examinar el comportamiento de la víctima, las reacciones y gestos de los acusados, la descripción, análisis e interpretación de los vídeos en los que se registran los hechos o la valoración de la pruebas psicológicas del comportamiento de la víctima. Además, el caso de la Manada ilustra la radical divergencia de interpretaciones de los hechos que se dan en la sentencia y en el voto particular. Mientras que en la sentencia se plantea que en uno de los videos se puede apreciar a la víctima «agazapada, acorralada contra la pared por dos de los procesados y gritando», en el voto particular los hechos son interpretados como una relación sexual consentida de carácter grupal. Nada de lo que observó e interpretó el Magistrado que emitió el voto particular lo llevó a sostener que existió un abuso sexual o una agresión sexual. ¿Cómo es que ante las mismas pruebas los Magistrados de la Audiencia Provincial de Navarra hayan llegado a interpretaciones radicalmente tan distintas?

La perspectiva de género podría servir para ilustrar, además, la manera en que las construcciones de género están presentes en la selección y formulación de los hechos jurídicamente relevantes. Como plantea Michele Taruffo, cuando se alude a un hecho en el contexto de los hechos jurídicamente relevantes a efectos de la decisión no se hace referencia a un dato absoluto «sino a una construcción lingüística y conceptual», "algo artificial que lleva la señal determinante del 'constructor' y de los presupuestos y los métodos que han guiado o condicionado la construcción» (TARUfFO, 2002: 108). Los hechos jurídicamente relevantes no serían solamente law-laden o rule-laden sino también culture-laden o value-laden.

En este sentido, el legislador selecciona y escoge qué hechos considera relevantes para la producción de ciertas consecuencias jurídicas (descartando otros), los formula de una determinada manera, determina qué hechos han de actualizarse para que se dé tal o cual consecuencia normativa. Es el legislador quien escoge y define que para cierta clase de delitos sexuales tiene que haber "ánimo lascivo» o que para acreditar la violencia intra-familiar se requería precisar y acreditar «circunstancias de tiempo, modo y lugar» ${ }^{16}$ o la manera de definir qué se entiende por violencia e intimidación para los delitos sexuales. Los órganos jurisdiccionales, a su vez, determinan si ciertos hechos encuadran en los hechos jurídicamente relevantes a través de criterios que no serían neutros. La formulación de cada uno de estos elementos y la manera en que

16 Este criterio fue adoptado por la Primera Sala de la Suprema Corte de Justicia de la Nación en México en la jurisprudencia 1a./J. 69/2006 de rubro DIVORCIO NECESARIO. CUANDO SE EJERCE LA ACCIÓN RELATIVA CON BASE EN LA CAUSAL DE VIOLENCIA INTRAFAMILIAR, EN LA DEMANDA DEBEN EXPRESARSE PORMENORIZADAMENTE LOS HECHOS, PRECISANDO LAS CIRCUNSTANCIAS DE TIEMPO, MODO Y LUGAR EN QUE OCURRIERON. Dicha jurisprudencia fue interrumpida en el año 2012. 
se entienden y configuran resulta en una operación que lleva la marca de quien lo formula y de los presupuestos y esquemas con los que lleva a cabo tal formulación.

Un aspecto adicional en el que la relación entre prueba y perspectiva de género puede ser analizada es el papel de las generalizaciones empleadas en el razonamiento probatorio. Marylin MacCrimmon ha planteado que la tradición racionalista de la prueba se basa en el presupuesto de una competencia cognitiva universal («the assumption of universal cognitive competence») (MACCRIMmON, 1991: 36 ss.) ${ }^{17}$. Este presupuesto consiste en que habría un conjunto común de enunciados, un repositorio o respaldo común de conocimientos («stock of knowledge» $\mathrm{o}$ «background knowledgess) con los que examinamos los hechos, el comportamiento humano, las actitudes de las personas, sus intenciones y su credibilidad. Dicho repositorio sería accesible a cualquier persona racional, de tal manera que cualquier persona llegaría a los mismos resultados.

La crítica a este presupuesto resultará familiar para quienes advierten el carácter vago, heterogéneo y en muchos casos infundado de los enunciados que los juristas suelen reconducir a la noción de máximas de experiencia o reglas de la sana crítica ${ }^{18}$. Sin embargo, MacCrimmon apunta a un aspecto que no suele ser advertido en los enfoques habituales sobre este tema, a saber, que muchas de las generalizaciones de sentido común que se emplean habitualmente en el razonamiento probatorio operan silenciando las experiencias de aquellas personas cuyo comportamiento no se adecua a la regla general.

De acuerdo con MacCrimmon, esta postura no tiene en cuenta que algunas de esas generalizaciones pueden no ser aplicables a las mujeres, o bien no a todas las mujeres en todas las circunstancias. Este tipo de generalizaciones son empleadas para examinar la credibilidad de los testigos, las inconsistencias en sus declaraciones, su comportamiento, la duda o inseguridad con la que hablan con independencia de la raza, género, edad o situación, asumiendo que todas las personas actúan, piensan o se comportan de la misma manera.

En palabras de MacCrimmon: «El presupuesto de una competencia cognitiva universal está en conflicto con la tesis feminista de que las diferentes experiencias y perspectivas de las mujeres no han sido incorporadas en la toma de decisiones jurídicas y que la incorporación de estas experiencias requiere de un examen autoconsciente y deliberativo de los esquemas y generalizaciones que operan en cada caso individual. No puede asumirse que las experiencias de las mujeres son parte del conocimiento de sentido común» (MACCrimmon, 1991: 39).

Para corregir este problema MacCrimmon plantea por un lado que habría que sustituir enunciados supuestamente generales por enunciados y esquemas que tomen

${ }^{17}$ El locus classicus de esta postura es L. Jonathan Cohen, 1977, párrafo 74, p. 274. En la traducción en español véase CoHen, 2017: 242.

18 Véase en este sentido el sugerente artículo «La sana crítica del juez, insana para el ejercicio de los derechos de las mujeres" de Martha Noya, 2016: 71-77. 
en cuenta las experiencias de las mujeres y que sean sensibles a diferentes tipos de situaciones. Y por el otro, que deberían admitirse pruebas periciales encaminadas a cuestionar y desactivar creencias y mitos habituales pero infundados.

Recapitulando, la tesis de Ramírez Ortiz sobre la función epistemológica y heurística de la prueba es sin duda un buen punto de partida para examinar la relación entre prueba y perspectiva. Pero la perspectiva de género tiene un alcance y unas pretensiones más amplias al abarcar la prueba en general, sus normas, prácticas (formales e informales), instituciones y presupuestos.

\section{TESTIGO ÚNICO Y EXIGENCIA DE CORROBORACIÓN}

Ramírez Ortiz sostiene que la perspectiva de género no puede emplearse para dar mayor fuerza probatoria a la declaración de la víctima, por lo que en el supuesto de que solamente existiera su declaración, sin ninguna otra prueba que corroborara su dicho, no podría tenerse por acreditada la hipótesis acusatoria. A su juicio, esta exigencia estaría apoyada en el recelo que históricamente ha recibido el testimonio único y el que autores como Bentham, Pagano o Beccaria advirtieran los riesgos de fundar una sentencia en un testimonio único. Ramírez Ortiz considera que la exigencia de corroboración encontraría respaldo, además, en el tránsito de una concepción subjetiva de la prueba a un sistema de valoración racional de la prueba y en la introducción de la presunción de inocencia como mecanismo de prevención de la arbitrariedad. De estas premisas se seguiría que la única manera de asegurar una verdadera convicción racional de la prueba que deje de lado una convicción meramente subjetiva de la declaración de la víctima es exigir que esté corroborada con un dato probatorio externo y de fuente distinta a la propia declaración.

A mi modo de ver, el argumento que plantea el Magistrado Ramírez Ortiz sobre la exigencia de corroboración de la declaración de la víctima es susceptible de examinarse con perspectiva de género.

En primer lugar, en cuanto al respaldo histórico de su tesis, Ramírez Ortiz hace un recorrido sobre la historia del testigo único en general sin distinguir la clase de delito o el contexto en el que se aplicaría esta tesis, como si la historia del testigo único fuera homogénea, confluyera hacia el mismo punto y fuera aplicable para toda clase de delitos, incluyendo delitos en los que difícilmente puede esperarse que haya otras pruebas como en los casos de violación ${ }^{19}$. Un análisis histórico del testimonio único con perspectiva de género plantearía la necesidad de tener en cuenta el contexto, hacer un análisis diferenciado de los delitos a los que podría aplicarse esta regla, sus distintas clases de justificación y la manera en que un criterio de esta naturaleza podría afectar a las mujeres en general o a las mujeres en cierta clase de delitos.

19 Un recuento histórico de la exigencia de corroboración en el delito de violación en Estados Unidos puede encontrarse en The Rape Corroboration Requirement: Repeal Not Reform, The Yale Law Journal, Vol. 81, No. 7 (Jun., 1972), pp. 1365-1391. 
Pero más allá de lo anterior, si bien es cierto que Bentham y otros autores advirtieron con razón sobre los riesgos del testimonio único, también es cierto que al examinar la prueba testimonial, el propio Bentham sostenía que habría una disposición a creer en la palabra del testigo. «La disposición a creer es el estado habitual y el no creer constituye un caso de excepción; para negarse a creer hace siempre falta una causa especial» (Bentham, 2001: 27). En este sentido, Bentham sostenía que habría una presunción de que lo que dice el testigo es conforme con la verdad. Pero incluso aunque no hubiera tal presunción, la regla sobre la insuficiencia del testimonio único refleja una gran desconfianza hacia la declaración de la víctima.

En segundo lugar, a partir de las premisa de las que parte Ramírez Ortiz no se sigue su conclusión. En efecto, la valoración racional de la prueba y el aseguramiento de la presunción de inocencia son dos componentes necesarios de un sistema de prueba que se precie de ser racional. Pero de ello no se sigue que sea necesario exigir la corroboración de la declaración de la víctima. La valoración de la prueba testimonial en general y de la declaración de la víctima en particular presenta sin duda espacios de apreciación y de subjetividad por parte del juez, pero de esto no se sigue que haya que prescindir de su declaración o considerarla completamente subjetiva a menos que esté corroborada con un dato externo.

Además, Ramírez Ortiz no plantea la corroboración como un criterio para valorar la declaración de la víctima sino como una auténtica exigencia. La corroboración dejaría de ser un criterio para valorar la prueba para convertirse en una auténtica regla de decisión ante la falta de prueba. Una regla que contribuiría a dar un mayor beneficio de duda al acusado que el que deriva de la presunción de inocencia y que en caso de ausencia de corroboración conllevaría automáticamente a la absolución. En este sentido, la perspectiva de género plantearía la necesidad de revisar la asignación del riesgo de error, incorporando en el análisis no solamente al acusado, sino también a las víctimas y las dificultades probatorias a las que se enfrentan en cierta clase de delitos como los delitos sexuales.

La exigencia de corroboración que plantea Ramírez Ortiz no opera aisladamente sino en conjunción con los criterios planteados por el Tribunal Supremo español para valorar la credibilidad de la víctima: ausencia de incredibilidad subjetiva, verosimilitud del testimonio y persistencia de la incriminación ${ }^{20}$. Como advierte Ramírez Ortiz, estos criterios han sido entendidos en ocasiones como verdaderas exigencias no como simples pautas o criterios orientadores (lo que ha llevado a sostener que la presencia de los tres parámetros convierte la declaración en prueba de cargo suficiencia o a que la ausencia de uno de ellos invalida el testimonio). Tales criterios pueden ser entendidos como criterios unívocos que debilitan la credibilidad del testimonio, pasando por alto que pueden ser compatibles tanto con la hipótesis acusatoria como con la hipótesis de la defensa. Un mal entendimiento de estos criterios puede reforzar

20 Estos criterios han sido tomados como modelos para examinar la declaración de la víctima en otras jurisdicciones como en el Perú. Acuerdo Plenario número. 2-2005/CJ-116 de la Corte Suprema de Justicia. 
la idea de testigos modélicos. Para que un testigo sea creíble su declaración tiene que ser coherente, consistente, debe tratarse de un relato plausible, debe haber ausencia de odio, resentimiento, venganza o enemistad, etc.

Pero esto no debería ser así. El hecho de que haya algunas inconsistencias, modificaciones, o estados subjetivos no demerita necesariamente la credibilidad de las declaraciones de las víctimas. Que un relato sea considerado plausible o implausible depende en buena medida de la manera en que se interpreten los hechos y de los criterios empleados para llevar a cabo la interpretación ${ }^{21}$.

Como señala Jordi Nieva (NIEva, 2010: 49-50): «el testimonio de la víctima puede no ser coherente, precisamente por el estrés postraumático», «es bastante sencillo que la víctima no pueda contextualizar parte de lo sucedido, y que tenga recuerdos solapados que le hagan incurrir en contradicciones», «y si por añadidura la víctima y el acusado se conocían personalmente, son esperables detalles oportunistas en la declaración de uno y otro». "Pero nada de ello es suficiente para dar por auténtico o falso el testimonio de cada uno». Precisamente por ello Nieva plantea que podría ser relevante acudir a una prueba pericial en materia de psicología, en el entendido de que si bien no es determinante, puede servir para valorar la declaración de la víctima en un mejor contexto.

Sin embargo, José Luis Ramírez Ortiz no solo advierte los problemas y márgenes de error que conlleva el análisis de la prueba psicológica sino que plantea que no elimina la necesidad de corroboración. La necesidad de someter a un juicio crítico la prueba pericial psicológica sobre la credibilidad del testimonio no solo es aplicable a esta prueba, sino a las pruebas en general, pudiendo obtenerse algunos elementos en apoyo de la credibilidad de la víctima, sin que esto suponga que sean determinantes $\mathrm{o}$ infalibles.

En suma, adoptar como exigencia que la declaración de la víctima esté corroborada por datos externos y no como un criterio de valoración de la prueba puede traducirse en una regla que opere en detrimento de las víctimas y que no hace sino reforzar un escepticismo estructural hacia su credibilidad, al tiempo que refuerza la impunidad de cierta clase de delitos, como los delitos sexuales.

\section{CONCLUSIÓN}

En este trabajo he querido realizar una aproximación inicial a la relación entre prueba y perspectiva de género a partir del texto de José Luis Ramírez Ortiz. Para ello he planteado tres puntos: (1) la conexión entre la perspectiva de género y las perspectivas feministas; (2) la potencial aplicación de la perspectiva de género a la prueba en general y (3) que la tesis sobre la exigencia de corroboración requiere examinarse con perspectiva de género. Es una regla que opera en detrimento de la víctima reforzando

${ }^{21}$ En relación con el análisis de credibilidad de relatos implausibles, véase Jones, 2002: 154 ss. 
el escepticismo hacia su credibilidad. Con estos planteamientos no se ha pretendido ofrecer un análisis exhaustivo de la relación entre prueba y perspectiva de género, sino simplemente poner sobre la mesa la necesidad de reflexionar críticamente sobre este tema y de sugerir algunas preguntas para explorar esta relación.

\section{BIBLIOGRAFÍA}

Bentham, J., 2001: Tratado de las pruebas judiciales, Granada: Comares.

Chils, M. Ellison, L. (eds.), 2000: Feminist perspectives on evidence, Cavendish Publishing Limited.

Di CoRleto, J. (ed.), 2017: «Igualdad y diferencia en la valoración de la prueba: estándares probatorios en los casos de violencia de género", en Género y justicia penal, Buenos Aires: Ediciones Didot.

Fuentes Soriano, O., 2009: El enjuiciamiento de la violencia de género, Iustel.

—, 2018: «Los procesos por violencia de género. Problemas probatorios tradicionales y derivados del uso de las nuevas tecnologías ", en Revista General de Derecho Procesal, 44

GonZÁlez Lagier, D., 2013: Quaestio facti, Fontamara.

HaAk, S., 1998, «Knowledge and Propaganda: Reflections of an Old Feminist » en Manifesto of a Passionate Moderate, The University of Chicago Press: 123-136

Kinports, K, 1991: «Evidence Engendered», en Illinois U. L. Rev., no. 2: 413 -456

Maccrimmon, M., 1991: "The social construction of reality and the rules of evidence ", en 25 U. Brit. Colum. L. Rev. 23: 36-50.

MACK, K, 1993: "Continuing barriers to women's credibility», Criminal Law Forum, 4, 2: 327-353.

Mackinnon C. A. 1982, "Marxist, Method and the State: An agenda for Theory», Signs, Vol. 7, No. 3: 515-544.

Nicolson, D, 2000, «Gender, espitemology and ethics: feminist perspectives on evidence theory», en Feminist perspectives on evidence, Cavendish Publishing Limited.

Noya, M. 2016. «La sana crítica del juez, insana para el ejercicio de los derechos de las mujeres», Tinkazos. Revista Bolivariana de Ciencias, núm. 39, pp.

Orenstein, A., 1999: "Feminism and evidence», en Taylor, B, Rush, S and Munro, R. J. (eds), Feminist Jurisprudence, Women and the Law-Critical Essays, Research Agenda and Bibliography, Littleton, Colorado: Fred B Rothman.

Ramírez Ortiz, J., Testimonio único de la víctima y perspectiva de género en el proceso penal de la presunción de inocencia, Quaestio facti, $\mathrm{xx}$

TARuffo, M., 2002: La prueba de los hechos, trad. Jordi Ferrer, Trotta.

TASLITZ, A., 1999: «Gender and race in feminine evidence policy: what feminism has to offer evidence law», en Southwestern U. L. Rev. 28, 171: 179-87.

— «The Rape Corroboration Requirement: Repeal Not Reform», 1972, en The Yale Law Journal, Vol. 81, No. 7: 1365-1391

Tubert, S., 2003: Del sexo al género. Los equívocos de un concepto, Cátedra. 